\title{
A CD22-reactive TCR from the T-cell allorepertoire for the treatment of acute Iymphoblastic leukemia by TCR gene transfer
}

\author{
Lorenz Jahn ${ }^{1}$, Renate S. Hagedoorn ${ }^{1}$, Dirk M. van der Steen ${ }^{1}$, Pleun Hombrink ${ }^{1,2}$, \\ Michel G.D. Kester ${ }^{1}$, Marjolein P. Schoonakker ${ }^{1}$, Daniëlle de Ridder $^{1}$, Peter A. van \\ Veelen $^{3}$, J.H. Frederik Falkenburg ${ }^{1}$, Mirjam H.M. Heemskerk ${ }^{1}$ \\ ${ }^{1}$ Department of Hematology, Leiden University Medical Center, 2300 RC Leiden, The Netherlands \\ ${ }^{2}$ Department of Hematopoiesis, Sanquin Research, 1006 AD Amsterdam, The Netherlands \\ ${ }^{3}$ Center for Proteomics and Metabolomics, Leiden University Medical Center, 2300 RC Leiden, The Netherlands \\ Correspondence to: Lorenz Jahn, email: I.jahn@lumc.nl \\ Mirjam H.M. Heemskerk, email: m.h.m.heemskerk@lumc.nl
}

Keywords: CD22, TCR gene transfer, immunotherapy, acute lymphoblastic leukemia, allogeneic HLA

Received: June 13, 2016 Accepted: September 19, $2016 \quad$ Published: September 26, 2016

\section{ABSTRACT}

CD22 is currently evaluated as a target-antigen for the treatment of B-cell malignancies using chimeric antigen receptor (CAR)-engineered T-cells or monoclonal antibodies (mAbs). CAR- and mAbs-based immunotherapies have been successfully applied targeting other antigens, however, occurrence of refractory disease to these interventions urges the identification of additional strategies. Here, we identified a TCR recognizing the CD22-derived peptide RPFPPHIQL $\left(C D 22_{\mathrm{RPF}}\right.$ ) presented in human leukocyte antigen (HLA)-B*07:02. To overcome tolerance to self-antigens such as CD22, we exploited the immunogenicity of allogeneic HLA. CD22 ${ }_{\mathrm{RPF}}$-specific T-cell clone 9D4 was isolated from a healthy HLA-B*07:02 ${ }^{\text {neg }}$ individual, efficiently produced cytokines upon stimulation with primary acute lymphoblastic leukemia and healthy B-cells, but did not react towards healthy hematopoietic and nonhematopoietic cell subsets, including dendritic cells (DCs) and macrophages expressing low levels of CD22. Gene transfer of TCR-9D4 installed potent CD22-specificity onto recipient CD8+ T-cells that recognized and lysed primary B-cell leukemia. TCR-transduced T-cells spared healthy CD22 ${ }^{\text {neg }}$ hematopoietic cell subsets but weakly lysed CD22 ${ }^{\text {low }}$ expressing DCs and macrophages. CD22-specific TCR-engineered T-cells could form an additional immunotherapeutic strategy with a complementary role to CAR- and antibody-based interventions in the treatment of B-cell malignancies. However, CD22 expression on non-B-cells may limit the attractiveness of CD22 as target-antigen in cellular immunotherapy.

\section{INTRODUCTION}

Immunotherapy for the treatment of hematological malignancies of the B-cell lineage using monoclonal antibodies $(\mathrm{mAb})$ or chimeric antigen receptor (CAR)modified T-cells has demonstrated clinical efficacy. Complete remissions have been achieved in chronic lymphocytic leukemia (CLL) and acute lymphoblastic leukemia (ALL) by CD19-targeting CAR T-cells [1-4]. CD20-specific $\mathrm{mAb}$ such as rituximab have been successfully applied in the treatment of B-cell malignancies [5-8]. Due to the high expression of CD19 and CD20 on malignant cells, these antigens can be efficiently targeted. Although healthy B-cells also express CD19 and CD20, and are depleted in the course of CAR or mAb treatment, long-term B-cell aplasia is tolerable and well manageable from a clinical perspective [4, 9-11]. However, emergence of antigen-loss tumorescape variants after administration of such interventions can pose a serious problem. Grupp et al. have reported on 13 out of 53 patients suffering from the relapse of CD19 ${ }^{\text {neg }}$ ALL after treatment with CD19-specific CAR $\mathrm{T}$ cells [12]. Although $76 \%$ of patient suffering from diffuse large B-cell lymphoma benefited from the addition of rituximab to standard chemotherapy [5], the overall survival is significantly worse in patients in need of 
second administration of rituximab treatment compared to rituximab-naïve patients (37\% vs $67 \%$ ) [13]. These outcomes highlight the importance to identify additional antigenic targets.

CD22 belongs to the sialic acid binding Ig-like lectin (Siglec) family [14]. CD22 is expressed at low levels on B-cell progenitors and strongly on mature B-cells. Via its extracellular domain CD22 binds to sialylated carbohydrates, while its intracellular domain contains immunoreceptor tyrosine-based inhibitory motifs (ITIMs) capable of activating phosphatases which in turn can dampen positive components of the B-cell receptor signaling cascade [15]. Therefore, CD22 acts predominately as an inhibitory coreceptor and plays an important role in BCR signaling threshold.

Due to the expression of CD22 not only on healthy but also malignant B-cells, CD22 is currently assessed as a target for CAR- and mAb-based immunotherapy approaches in the treatment of mainly ALL and B-cell lymphoma [16-19].

Besides CAR- and mAb-based strategies, the administration of T-cell receptor (TCR)-modified T-cells has emerged as a promising intervention of solid tumors $[20,21]$. TCRs induce T-cell activation by binding to cognate antigen-derived peptides presented on the cell surface in the context of major histocompatibility complex (MHC). Since MHC molecules sample the cell's proteome, TCRs can target peptides derived from intra- and extracellular proteins. Hence, TCRs can still efficiently target antigens whose extracellular abundance may be insufficient to be susceptible to CAR- or mAbbased immunotherapies. Therefore, TCR-modified T-cells form an additional avenue in the exploitation of promising antigenic targets.

Here, we describe the identification of a TCR specifically recognizing the CD22-derived peptide $\mathrm{CD} 22_{\mathrm{RPF}}$ presented in the context of the human leukocyte antigen (HLA)-B*07:02. To effectively target self-antigens such as CD22, we exploited the immunogenicity of allogeneic (non-self) HLA (alloHLA). From an HLA-B7 ${ }^{\text {neg }}$ healthy individual we isolated T-cell clone 9D4 that expressed a CD22 ${ }_{\mathrm{RPF}^{-}}$ specific TCR. Clone 9D4 recognized HLA-B7pos primary ALL samples, ALL cell lines and healthy B-cells. Using TCR gene transfer, TCR-9D4 modified CD8 ${ }^{+}$T-cells recognized and lysed primary ALL samples, ALL cell lines, and healthy B-cells. TCR-transduced T-cells did not produce cytokine upon stimulation with but weakly lysed dendritic cells (DCs) and macrophages expressing low levels of CD22. CD22-specific TCRengineered T-cells could form an additional strategy to exploit CD22 as antigenic target in immunotherapy of B-cell malignancies. However, due to the expression of CD22 on non-B-cells, our data also indicate potential limitations of CD22 as a target-antigen in cell-based immunotherapeutic strategies.

\section{RESULTS}

\section{Identification of a CD22 epitope}

From the HLA-ligandome of B lymphocytes [22], we identified a CD22-derived nonameric peptide RPFPPHIQL (CD22 $\left.2_{\mathrm{RPF}}\right)$, that is naturally processed and presented in the context of HLA class I. Matching mass spectrometry fragmentation patterns of synthesized and eluted peptide indicated correct identification (Supplementary Figure S1). Using a public prediction algorithm $[23,24]$, peptide $\mathrm{CD} 22_{\mathrm{RPF}}$ was designated to be a strong binder for HLA-B*07:02 (HLA-B7). This prediction was supported by the formation of stable peptide-MHC ( $\mathrm{pMHC}$ ) monomers composed of CD22 $2_{\mathrm{RPF}}$ and HLA-B7.

\section{Isolation of CD22-reactive T-cell clone 9D4}

To isolate CD22-reactive T-cell clones, we used pMHC-tetramers composed of CD22 ${ }_{\text {RPF }}$ bound HLA-B7. Starting with 250 to $1,000 \times 10^{6}$ peripheral blood mononuclear cells (PBMCs) from six healthy HLA-B7 ${ }^{\text {neg }}$ individuals, pMHC-tetramer-binding cells were first enriched by magnetic activated cell sorting (MACS). From the positive cell fraction, containing pMHC-tetramer binding cells, hundreds of pMHC-tetramer ${ }^{+} \mathrm{CD}^{+} \mathrm{T}$-cells were then acquired by single-cell FACSorting and clonally expanded for two weeks. From the expanding clones, 7 CD22-reactive T-cell clones were identified based on their reactivity towards K562 cells expressing HLA-B7 (K562-B7) exogenously loaded with CD22 ${ }_{\mathrm{RPF}}$ in the absence of reactivity towards unloaded K562-B7 cells. Among these 7 T-cell clones, clone 9D4 demonstrated highest peptide sensitivity when stimulated with titrated amounts of $\mathrm{CD} 22_{\mathrm{RPF}}$ and robust recognition of three HLA-B7 ${ }^{\text {pos }}$ CD22-expressing Epstein-Barr virus (EBV)transformed B-lymphoblastic cell lines (B-LCLs) (Figure 1A-1C). In contrast, other clones, as exemplified by clone 62 , required high amounts of exogenous peptide to be stimulated and failed to recognize endogenously processed antigen (Figure 1A-1C).

Reactivity towards stimulator cells by clone 9D4 was CD22 dependent as introduction of CD22 into otherwise CD22-negative K562-B7 resulted in their recognition (Figure 1D).

In summary, high avidity CD22-reactive T-cell clone 9D4 was isolated from an HLA-B7 ${ }^{\text {neg }}$ healthy individual by using pMHC-tetramers composed of peptide CD22 $2_{\mathrm{RPF}}$ bound to HLA-B7. Clone 9D4 recognized endogenously processed and presented peptide $\mathrm{CD} 22_{\mathrm{RPF}}$.

\section{Recognition of B-cell malignancies by clone 9D4}

We tested the capacity of clone 9D4 to recognize HLA-B ${ }^{\text {pos }}$ B-cell malignancies. Clone 9D4 was stimulated 
with samples from patients at diagnosis suffering from acute lymphoblastic leukemia (ALL) and ALL cell lines (Figure 2A). Clone 9D4 recognized all 4 primary ALL samples and both ALL cell lines with varying degrees of cytokine secretion in response to each sample. FACS analysis demonstrated that cell surface expression of CD22 varied between samples (Figure 2B). Normal B-cells and ALL cell line ALL-VG demonstrated highest CD22 expression followed by ALL-BV. CD22 was expressed to lower degrees on primary ALL samples. CD22 cell surface expression correlated with CD22 mRNA expression (data not shown). However, although ALL samples MMX had lower CD22 expression compared to sample MRQ, both samples were equally well recognized, indicating that also reduced levels of CD22 can be detected by this T-cell clone.

These data indicated that CD22-reactive T-cell clone 9D4 can recognize CD22-expressing primary HLA-B7pos B-cell malignancies such as ALL.

\section{B-cell-restricted recognition profile of clone 9D4}

To investigate potential on- and off-target toxicity, T-cell clone 9D4 was stimulated with a panel of HLAB $7^{\text {pos }}$ healthy hematopoietic and nonhematopoietic cell subsets. No recognition of 3 fibroblasts was observed (Figure 3A). Moreover, clone 9D4 did not react towards fibroblasts that had been cultured in the presence of IFN- $\gamma$ to simulate inflamed conditions.

When cocultured with primary hematopoietic cells of three healthy HLA-B7pos individuals, T-cell clone 9D4 did not react towards T-cells, CD14 $4^{+}$monocytes or CD34 hematopoietic precursor cells (HPCs) (Figure 3B-3C). On the other hand, clone 9D4 weakly recognized CD22- expressing primary and activated B-cells. Furthermore, no IFN- $\gamma$ production of clone 9D4 was observed towards monocyte-derived immature and mature dendritic cells (DCs), and type I and II macrophages although low levels of mRNA and cell surface-expressed CD22 was detected in these cell samples (Figure 3D-3E and 3G). Clone 9D4 did not produce any GM-CSF upon stimulation with DCs or macrophages (data not shown). A control T-cell clone specific for a ubiquitously expressed antigen verified the stimulatory capacity of all tested cell samples (Supplementary Figure S2).

Finally, clone 9D4 showed no reactivity with other HLA class I molecules other than HLA-B7 when stimulated with a panel of B-LCLs expressing ca. 95\% of common and rare HLA class I alleles [25] (Figure 3F and Supplementary Table S1).

In summary, these data indicated a safe reactivity profile of clone 9D4; CD22-expressing healthy B-cells were weakly recognized whereas no reactivity towards nonhematopoietic and hematopoietic cells not belonging to the B-cell compartment was observerd. Furthermore, clone 9D4 demonstrated a strong HLA-B7 dependency with no reactivity towards other tested HLA class I alleles.

\section{CD22 reactivity of TCR-modified T-cells by TCR gene transfer}

We sequenced the TCR of clone 9D4 (TCR-9D4) and constructed a retroviral vector which allows for the transduction of recipient T-cells. To enhance cell surface expression and preferential pairing of the introduced TCR alpha and beta chain, the $\mathrm{V}(\mathrm{D}) \mathrm{J}$ regions of TCR-9D4 were codon-optimized and fused to murine TCR constant
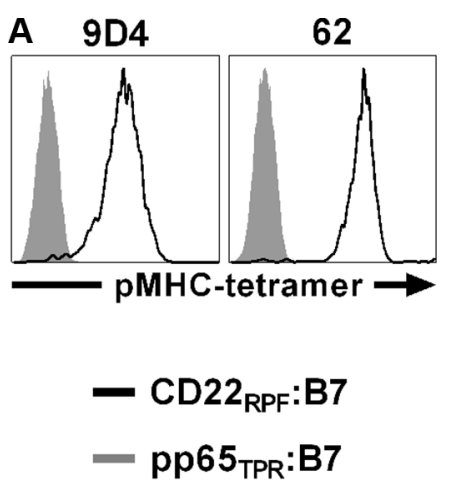
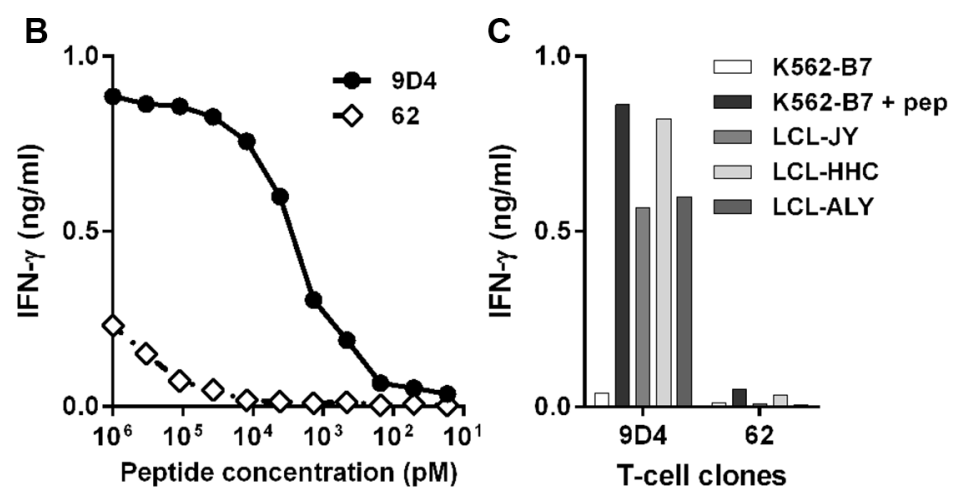

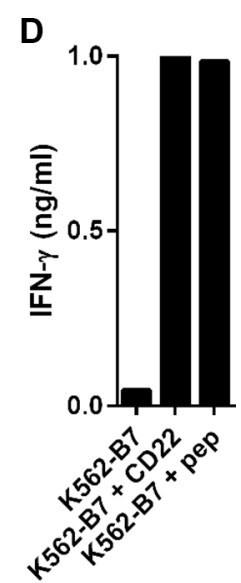

Figure 1: Identification of CD22-reactive T-cell clone 9D4 from an HLA-B7 ${ }^{\text {neg }}$ healthy individual. T-cell clones were isolated from HLA-B7 $7^{\text {neg }}$ healthy individuals by pMHC-tetramers composed of CD22 $2_{\mathrm{RPF}}$ bound to HLA-B7 (CD22 $: \mathrm{R} 7$ ) (black), and selected for CD22 specificity. (A) Shown are histograms of two representative T-cell clones stained with specific pMHC-tetramer $\mathrm{CD} 22_{\mathrm{RPF}}: \mathrm{B} 7$ or a control pMHC-tetramer composed of pp65-derived peptide TPRVTGGGAM bound to HLA-B7 (pp65 $: \mathrm{TP}$ ) (gray). (B-C) T-cell clones 9D4 and 62 were co-cultured with CD22 ${ }^{\text {neg }} \mathrm{K} 562-\mathrm{B} 7$ cells exogenously loaded with peptide CD22 $2_{\mathrm{RPF}}$ (B) or three HLAB7 ${ }^{\text {pos }}$ B-LCLs naturally expressing CD22 (C) at 1:15 responder-to-stimulator ratio. (D) T-cell clone 9D4 was incubated with K562-B7 cells stably transduced to express CD22 (K562-B7 + CD22). K562-B7 loaded with peptide CD22 ${ }_{\mathrm{RPF}}$ (K562-B7+ pep) served as positive control. Shown are means of one representative experiment carried out in duplicate. 
domains. Retroviral transduction of recipient $\mathrm{CD} 8^{+} \mathrm{T}$-cells led to cell surface expression of TCR-9D4 measured by staining of the murine TCR beta constant domain and binding to pMHC-tetramer CD22 ${ }_{\mathrm{RPF}}: \mathrm{B} 7$ (Figure 4A). TCR-transduced $\mathrm{CD}^{+} \mathrm{T}$-cells highly recognized CD22expressing stimulator cells comparable to the parental clone 9D4 (Figure 4B). The recognition was specific since mock-transduced T-cells failed to produce any cytokine upon stimulation, except for some background cytokine secretion against EBV-transformed LCL-JY most likely caused by the presence of EBV-reactive T-cells. When stimulated with a panel of primary B-cell malignancies, TCR-transduced but not mock-transduced T-cells produced IFN- $\gamma$ upon coincubation (Figure 4C). TCRengineered T-cells reacted towards all 4 ALL samples and both tested ALL cell lines with different amounts of IFN- $\gamma$ production. Furthermore, CD22-specific TCRtransduced T-cells and parental clone 9D4 lysed primary ALL and ALL cell lines (Figure 4D). Lysis of primary ALL and ALL cell lines was comparable although CD22 expression differed between samples as shown previously in Figure 2B. Cell lysis was specific as CD22 ${ }^{\text {neg }} \mathrm{K} 562-\mathrm{B} 7$ cells were not recognized by either TCR-modified T-cells or the parental clone. Furthermore, mock-transduced T-cells did not lyse any sample indicating that reactivity towards target cells was introduced with TCR gene transfer. In addition, TCR-modified T-cells proliferated when cocultured with a CD22-expressing stimulator cell line K562-B7 + CD22 and ALL-VG but did not expand in the presence of CD22 ${ }^{\text {neg }}$ stimulators such as autologous T-cells or K562-B7 (Figure 4E).

When stimulated with healthy hematopoietic cell subsets of autologous origin, TCR-transduced T-cells did not react towards primary B-cells but recognized activated B-cells (Figure 5A). In contrast, TCR-engineered T-cells did not produce IFN- $\gamma$ upon stimulation with primary or activated T-cells, primary CD14+ monocytes or monocytederived immature and mature DCs, and type I and II macrophages (Figure 5B). When tested for their lytic capacity, TCR-modified T-cells lysed autologous primary
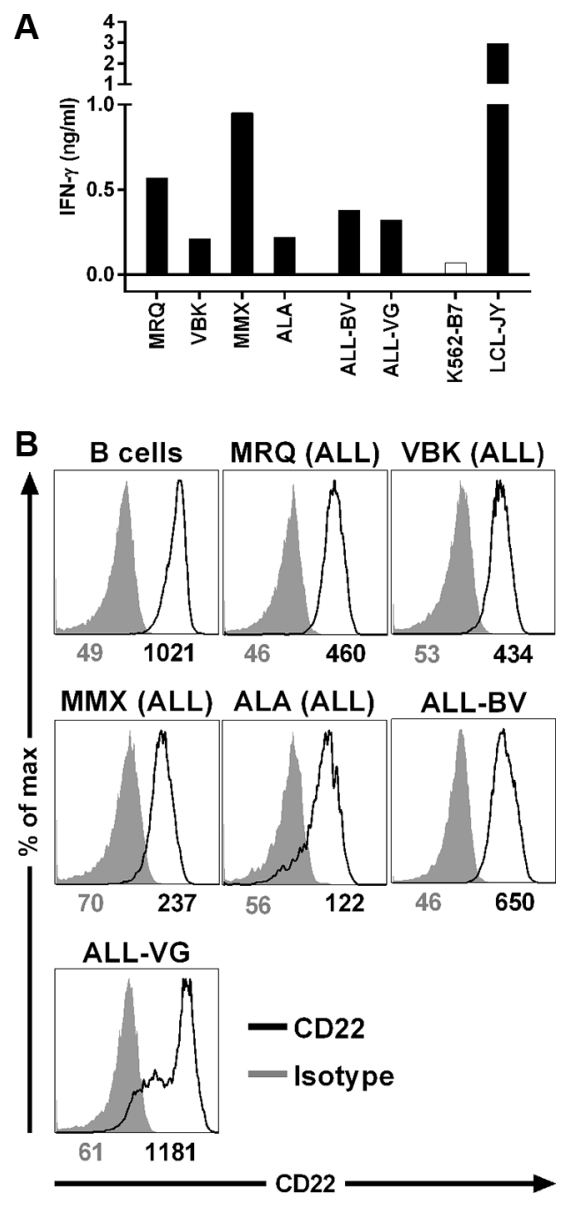

Figure 2: Recognition of B-cell malignancies by T-cell clone 9D4. (A) CD22-specific T-cell clone 9D4 was cocultured with primary HLA-B7 ${ }^{\text {pos }}$ acute lymphoblastic leukemia (ALL; MRQ, VBK, MMX, and ALA) or two ALL cell lines (ALL-BV and ALL-VG) at a 1:25 responder-to-stimulator ratio. CD22 ${ }^{\text {neg }}$ K562-B7 cells and CD22 ${ }^{\text {pos }}$ LCL-JY served as negative and positive control, respectively. (B) Shown are histograms of primary malignant B-cell samples and ALL cell lines stained with a CD22-specific antibody (black) or an isotype control (gray). Samples include primary ALL and ALL cell lines used to stimulate clone 9D4 in (A). Healthy B-cells served as positive control. Numbers under histograms indicate mean fluorescent intensity of respective peak. 


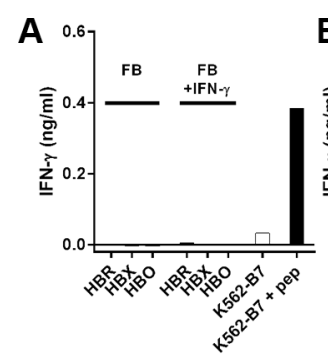

D

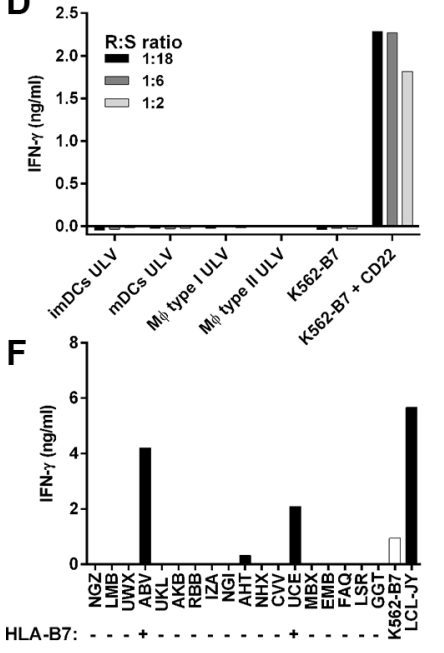

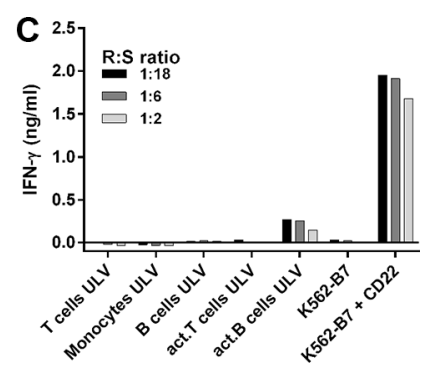

$\mathrm{E}$

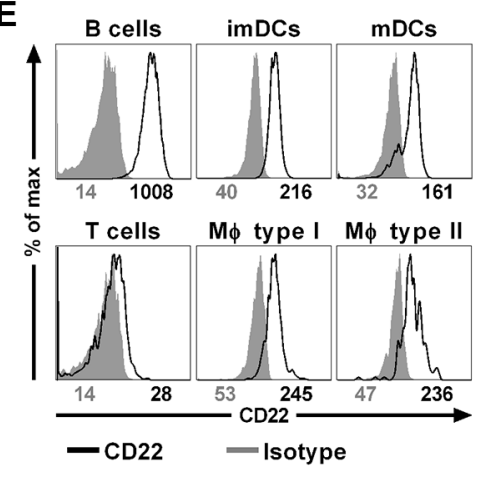

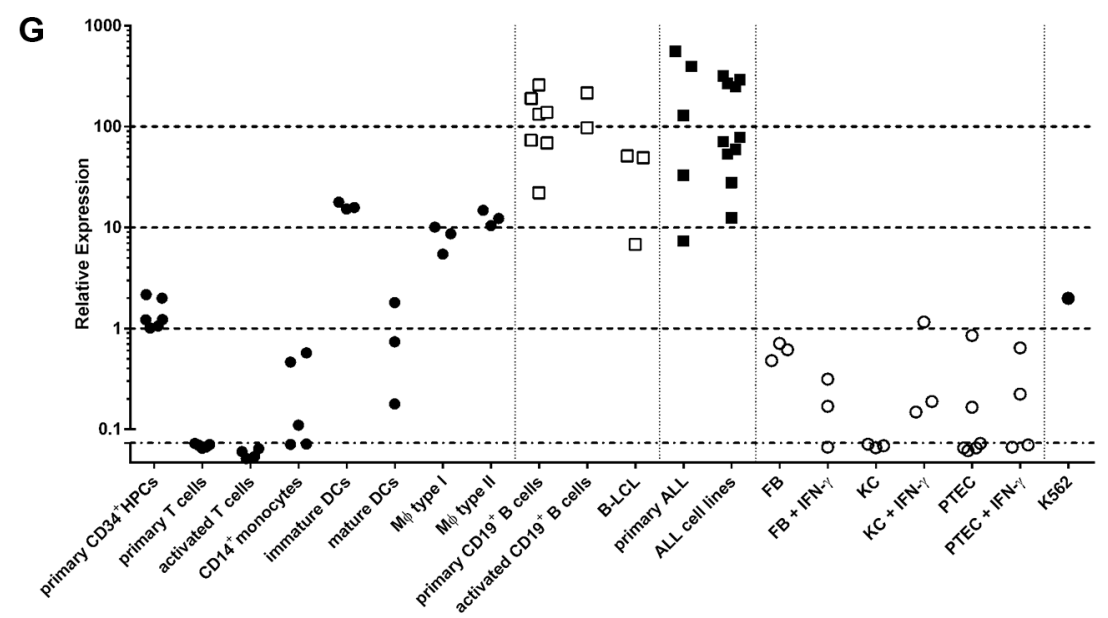

Figure 3: B-cell-restricted reactivity profile of T-cell clone 9D4. (A) Clone 9D4 was coincubated with HLA-B7pos Fibroblast (FB) from three healthy individuals (HBR, HBX, HBO) at a 1:6 responder-to-stimulator ratio. Fibroblasts were treated with IFN- $\gamma$ $(\mathrm{FB}+\mathrm{IFN}-\gamma)$ for 4 days prior to experiment to simulate inflamed conditions. CD22 ${ }^{\text {neg }} \mathrm{K} 562-\mathrm{B} 7$ served as negative control. K562-B7 pulsed with CD22 $2_{\text {RPF }}\left(+\right.$ pep) served as positive control. (B-D) Healthy hematopoietic cell subsets from 5 different HLA-B $7^{\text {pos }}$ individuals (UHK, UDR, ALY, AFD, ULV) were coincubated with clone 9D4 at various responder-to-stimulator (R:S) ratios. Primary T cells, monocytes, B cells, and hematopoietic progenitor cells (HPCs) were isolated from cryopreserved material (B). T cells were stimulated with PHA (act. T cells). B cells were stimulated with CD40L (act. B cells) (C). Immature and mature dendritic cells (imDCs and mDCs, respectively), and type I and II macrophages (MФ type I and type II, respectively) were monocyte-derived (D). CD22 ${ }^{\text {neg }} \mathrm{K} 562-\mathrm{B} 7$ served as negative control. K562-B7 pulsed with CD22 $2_{\mathrm{RPF}}(+$ pep) or expressing CD22 (+ CD22) served as positive control. (E) Shown are histograms of various healthy hematopoietic subsets stained with a CD22-specific antibody (black) or an isotype control (gray). Numbers under histograms indicate mean fluorescent intensity of respective peak. (F) Clone 9D4 was cocultured with HLA-B7 ${ }^{\text {pos }}$ B-LCLs $(+)$ or HLA-B $7^{\text {neg }}$ B-LCLs $(-)$ as indicated on the $\mathrm{x}$-axis at a 1:15 responder-to-stimulator ratio. CD22 $2^{\text {neg }} \mathrm{K} 562-\mathrm{B} 7$ and LCL-JY served as negative and positive control, respectively. A complete list of all HLA class I and II molecules present can be found in Supplementary Table S1. (G) CD22 mRNA expression was measured in various hematopoietic and non-hematopoietic cell subsets by quantitative real-time PCR. Shown are samples of healthy hematopoietic origin (black dots), healthy B-cells (clear squares), B-cell malignancies (black squares) and samples of non-hematopoietic origin (clear dots). Individual dots indicate individual samples. Average expression in healthy B-cells was set to 100. Fibroblasts (FB), keratinocytes (KC) and proximal tubular epithelial cells (PTEC) were cocultured in the presence of IFN- $\gamma(+$ IFN- $\gamma)$ for 4 days to simulate inflammation. 

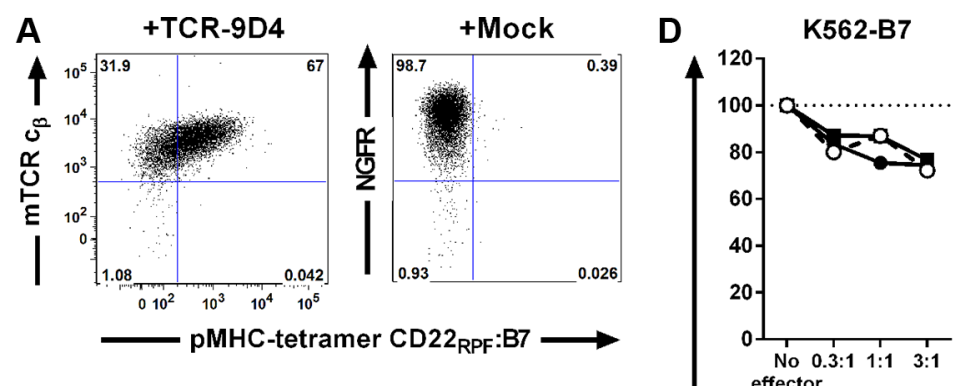

B
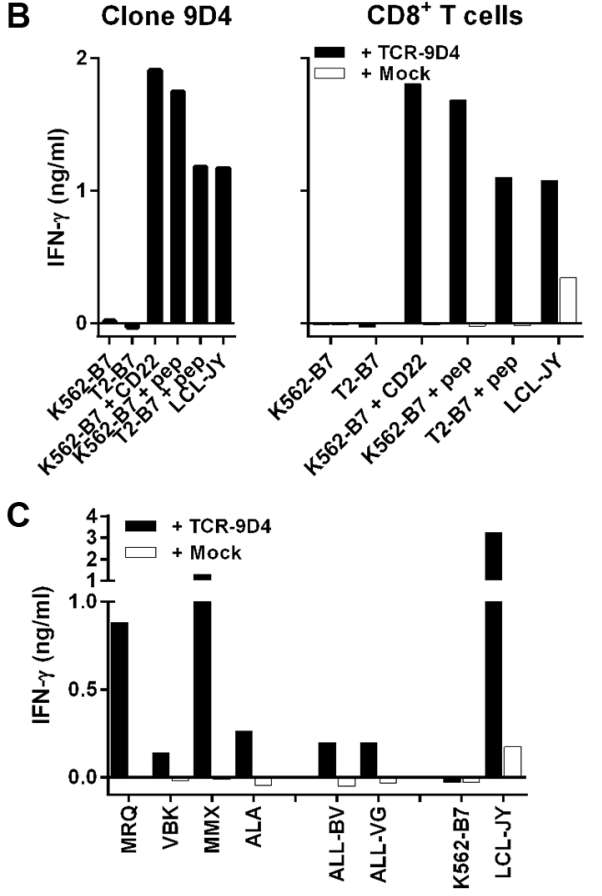

CD8 $^{+}$T cells
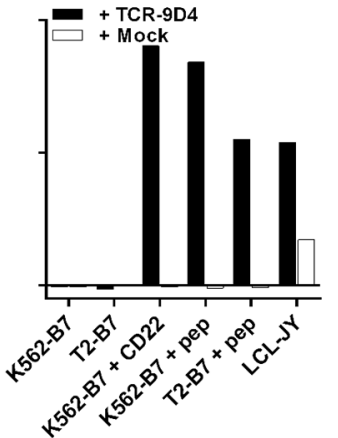

ALL-BV

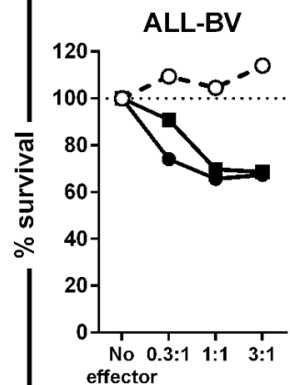

ALL VBK

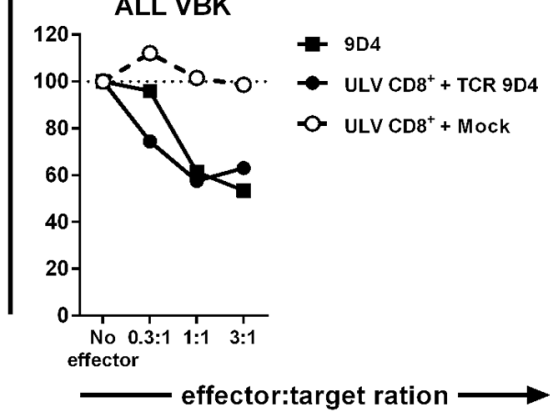

K562-B7 + CD22

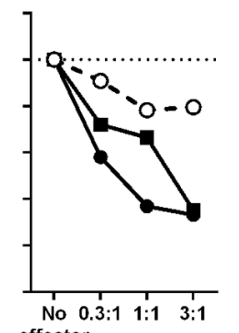

effector

ALL-VG

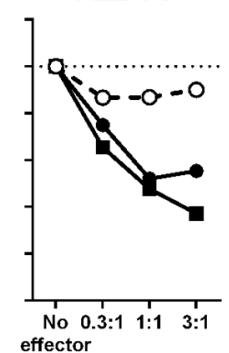

$$
\text { No } 0.3: 1 \quad 1: 1 \quad 3: 1
$$

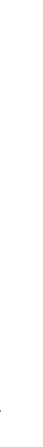

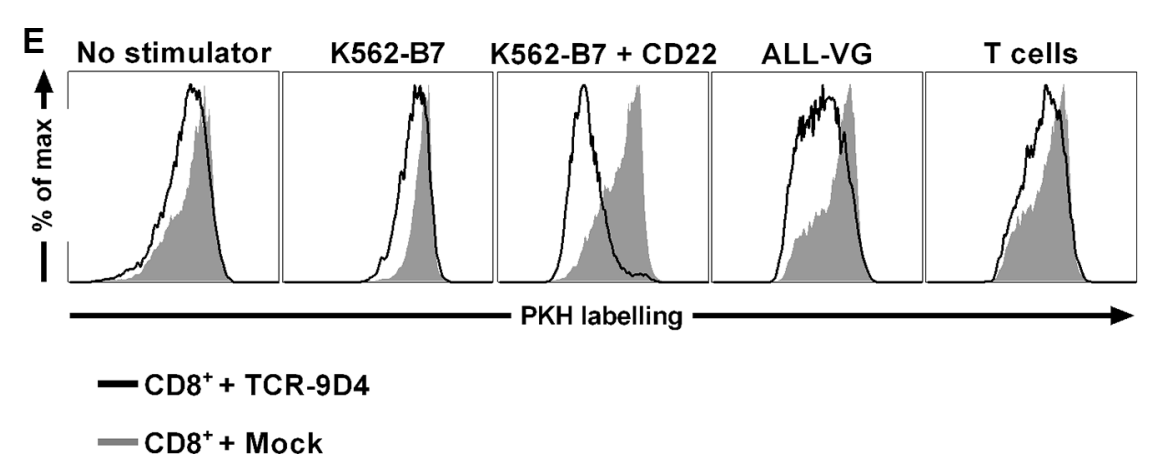

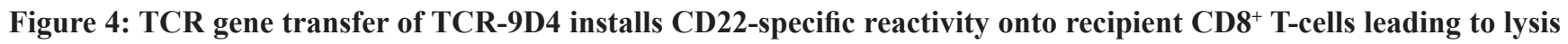
of B-cell malignancies. Retroviral transduction was used to introduce the TCR of clone 9D4 (TCR-9D4) in recipient CD8 ${ }^{+}$T-cells of an HLA-B $7^{\text {pos }}$ healthy individual. An empty expression vector containing NGF-R as marker gene served as control (+ Mock) (A) Shown are dot plots of purified CD8 ${ }^{+}$T-cells transduced with TCR-9D4 or mock-transduced stained with pMHC-tetramer CD22 $2_{\mathrm{RPF}}$ :B7. Transduction is monitored with an antibody binding to the murine TCR beta constant domain ( $\mathrm{mTCR} \mathrm{c}_{\beta}$ ) of TCR-9D4 or a NGF-R-specific antibody. (B) Original clone 9D4, purified TCR- or mock-transduced CD8 ${ }^{+}$T-cells were stimulated with CD22 $2^{\text {neg }}$ K562-B7 cells or T2 cells expressing HLA-B7 (T2-B7), K562-B7 cells expressing CD22 (+ CD22), K562-B7 and T2-B7 cells pulsed with exogenous peptide CD22 2 (+ pep), and CD22-expressing LCL-JY at a 1:15 responder-to-stimulator ratio. (C) Transduced T-cells were stimulated with HLA-B7pos primary acute lymphoblastic leukemia MRQ, VBK, MMX, and ALA or two ALL cell lines (ALL-BV and ALL-VG). CD22 ${ }^{\text {neg }}$ K562-B7 cells and CD22-expressing LCL-JY served as negative and positive control, respectively. (D) Original clone 9D4, TCR- or mock-transduced T-cells were cocultured with different HLA-B $7^{\text {pos }}$ target cells at various effector-to-target ratios. Targets include two ALL cell lines (ALL-BV and ALL-VG) and primary ALL sample (VBK). Surival of target cells was assessed after 20 hours of coincubation. Shown are means of one experiment carried out in triplicate. (E) PKH-labelled TCR- or mock-transduced T-cells were cocultured with various irradiated stimulator cells for 5 days at 1:5 responder-to-stimulator ratio. 
and activated B-cells (Figure 5C). Although weak lytic activity against immature DCs and type I macrophages was seen, no lysis of primary or activated T-cells, CD14 monocytes or monocyte-derived type II macrophages was observed whereas a control T-cell clone lysed all target cells.

In summary, gene transfer of TCR-9D4 installed CD22-specific reactivity onto $\mathrm{CD}^{+}$T-cells. TCRtransduced $\mathrm{CD}^{+}$T-cells recognized and lysed primary B-cell malignancies, healthy B-cells and to a lesser degree also immature DCs and type I macrophages. No reactivity towards other $\mathrm{CD} 22^{\text {neg }}$ healthy hematopoietic cell subsets outside of the B-cell compartment was observed.

\section{DISCUSSION}

Here, we describe the identification of a CD22specific TCR directed against the CD22-derived peptide RPFPPHIQL presented in the context of HLA-B7. TCR gene transfer installed CD22 reactivity onto recipient
T-cells which recognized and lysed CD22-expressing primary ALL samples, ALL cell lines, and B-cells, while sparing healthy nonhematopoietic and hematopoietic cell subsets. However, although clone 9D4 or TCR-modified T-cells did not produce IFN- $\gamma$ upon stimulation with DCs or macrophages, these cell subsets were weakly lysed and demonstrated low levels of CD22 expression.

This high affinity CD22-specific TCR was identified from T-cell clone 9D4 which was isolated from an HLA-B7 ${ }^{\text {neg }}$ healthy individual. By exploiting the immunogenicity of allogeneic HLA, T-cell clones carrying high affinity TCRs specific for self-antigens such as CD22 can be raised. T-cell clone 9D4 demonstrated great peptide specificity, a feature also observed for other T-cell clones raised in an HLA-mismatched setting after allogeneic stem cell transplantation [26, 27]. In addition, other groups have reported comparable observations when inducing T-cell response across an HLA-mismatch in vitro [28-31].
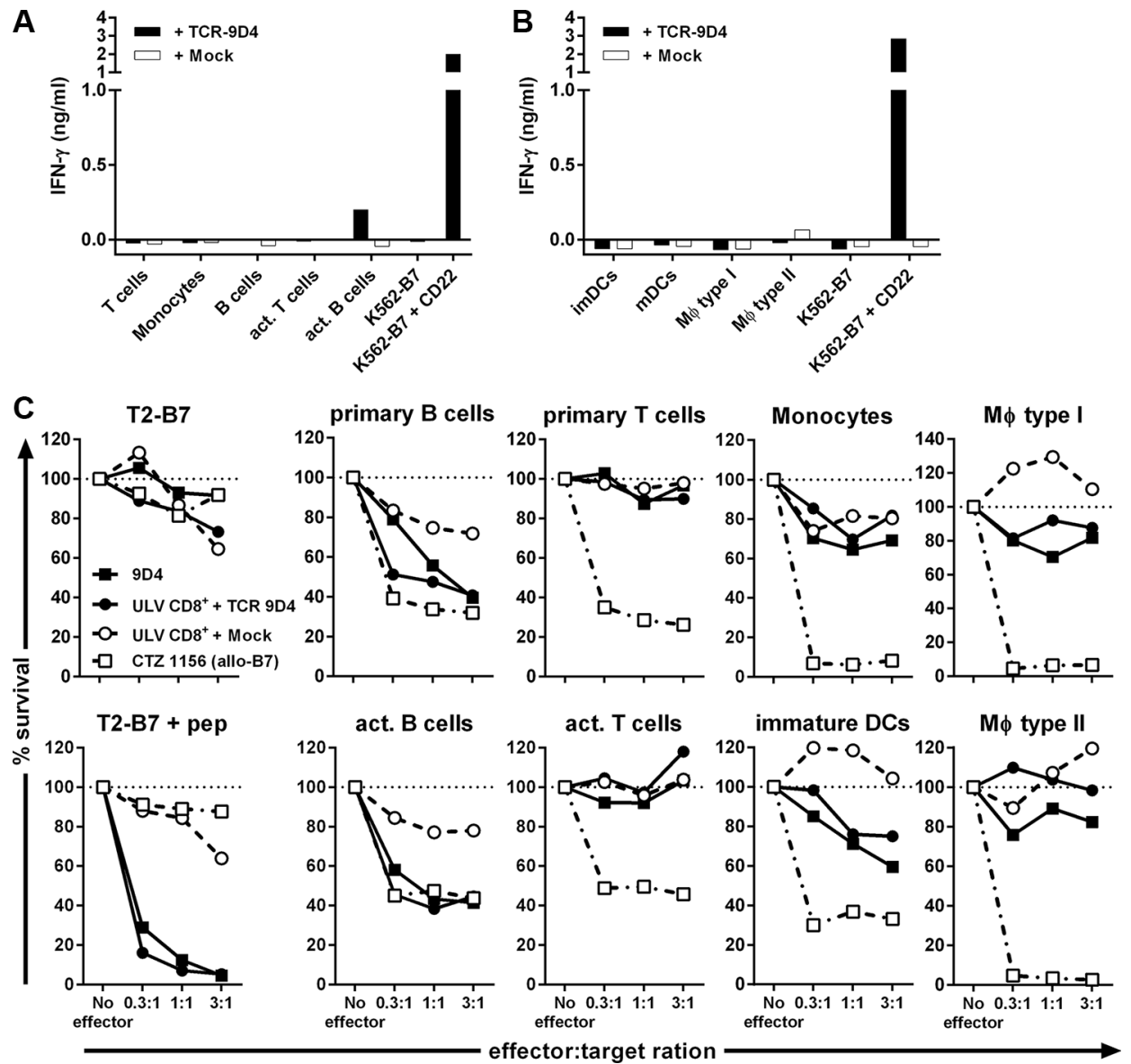

Figure 5: Off-tumor on-target toxicity of CD22-specific $\mathrm{T}$ cells caused by CD22 expression on dendritic cells and macrophages. $\mathrm{CD} 8^{+}$T-cells of an HLA-B7 ${ }^{\text {pos }}$ individual were retrovirally transduced to express either TCR-9D4 (+ TCR-9D4) or an empty vector (+ Mock). (A-B) Purified TCR- or mock-transduced CD8 ${ }^{+}$T-cells were stimulated with hematopoietic cell subsets of autologous origin. (C) Original clone 9D4, purified TCR- or mock-transduced CD8 ${ }^{+}$T-cells, or control clone CTZ were cocultured with T2-B7 cells or T2-B7 cells pulsed with peptide CD22 $2_{\mathrm{RPF}}(+$ pep), or hematopoietic cell subsets derived from the same origin as TCR- and mock-transduced T-cells (autologous setting). Survival of target cells was assessed after 20 hours of coculture. Shown are means of one experiment carried out in triplicate. 
T-cell clone 9D4 was selected because it demonstrated highest peptide sensitivity amongst all isolated CD22-specific T-cell clones. Clone 9D4 specifically produced cytokines upon stimulation with all 4 primary ALL samples, both ALL cell lines and normal B-cells. However, we could not establish a clear correlation between antigen expression levels and degree of cytokine production for Clone 9D4 and T-cells transduced with the CD22-specific TCR. Besides expression levels of the antigen, additional factors such as HLA molecule abundance and presence of other costimulatory and adhesion molecules on target cells may account for this difference in sensitivity. Nonetheless, primary ALL, ALL cell lines, and normal B-cells could be lysed by clone 9D4 and TCR-modified T-cells. Furthermore, clone 9D4 and TCR-engineered T-cells weakly lysed DCs and macrophages in the absence of IFN- $\gamma$ production, indicating that also cells with low levels of CD22 expression can be targeted.

The expression of CD22 on non-B-cells such as DCs and macrophages poses direct limitations of CD22 as a target-antigen in immunotherapy. While permanent eradication of the B-cell lineage is permissible and hypogammaglobulinemia is clinically manageable, ablation of the dendritic cell and type I macrophage compartment is most likely not tolerable long-term. To prevent long-term depletion of the dendritic cell and macrophage compartment TCR-engineered T-cells could additionally be equipped with suicide genes to deplete the administered T-cell product from circulation after successful eradication of the malignancy [32-34]. Such a strategy could limit the potential toxicity towards undesired cell subsets, however, may also increase the chance of relapse of the malignancy once tumorsurveilling TCR-engineered T-cells have been depleted from circulation.

It should also be noted that we observed CD22 cell surface expression on DCs and macrophages which has also been reported by others [35]. Therefore, these cell subsets could be affected by on-target off-tumor toxicity of CD22-specific mAbs or CAR-engineered T-cells. No toxicity on the myeloid lineage has been described for the CD22-targeting mAb epratuzumab. However, CD22 is currently also evaluated as a target for CAR-based immunotherapies with several trials recruiting patients (www.clinicaltrial.gov). Since CAR-engineered T-cells require less antigen than $\mathrm{mAbs}$ [36] and can persist long term in patients, this potential off-tumor toxicity should be considered in clinical trial design.

In summary, T-cells engineered to express a CD22specific TCR could be a treatment option in patients suffering from CD22 ${ }^{\text {pos }}$ B-cell malignancies. However, while CD22-targeting may be feasible in antibody-based approaches, our study highlights potential limitations of CD22 as an ideal antigenic target for cellular immunotherapeutic interventions.

\section{MATERIALS AND METHODS}

\section{Culture conditions and cells}

All studies using human material were approved by the Leiden University Medical Center ethical review board. Peripheral blood was obtained from healthy individuals or patients after informed consent. PBMCs were isolated using Ficoll-gradient centrifugation and were cryopreserved. Primary hematopoietic cell subsets were obtained from cryopreserved PBMCs of HLA$\mathrm{B}^{*} 07: 02^{\text {pos }}$ healthy donors that were incubated with either anti-CD4, anti-CD8, anti-CD14, anti-CD19 or antiCD34 magnetic microbeads (Miltenyi Biotec, Bergisch Gladbach, Germany) for $15 \mathrm{~min}$ at $4^{\circ} \mathrm{C}$. Microbeadlabeled cells were isolated on LS column (Miltenyi Biotec) according to manufacturer's protocol. Purity of isolated cells was assessed using FACS analysis and cells were only used in experiments if purity exceeded 95\%. T-cells were cultured in T-cell medium consisting of IMDM (Lonza, Basel, Switzerland) supplemented with 100 IU/ml IL-2 (Proleukine; Novartis Pharma, Arnhem, The Netherlands), 5\% fetal bovine serum (FBS; Gibco, Life Technologies, Carlsbad, CA) and 5\% human serum. Activated T-cells were generated by stimulating $\mathrm{CD}^{+}$ and $\mathrm{CD}^{+}$T-cells with irradiated $(35 \mathrm{~Gy}$ ) feeders in a $1: 5$ ratio in T-cell medium supplemented with $0.8 \mu \mathrm{g} / \mathrm{ml}$ phytohemagglutinin (PHA; Biochrom AG, Berlin, Germany) for 10 days prior to experiment. Immature and mature DCs were differentiated in vitro from isolated $\mathrm{CD}_{14}{ }^{+}$cell populations. Briefly, on day zero $1 \times 10^{6}$ cells $/ \mathrm{ml}$ were seeded in IMDM supplemented with $100 \mathrm{ng} / \mathrm{ml} \mathrm{GM-}$ CSF (Sandoz Novartis Pharma, Almere, The Netherlands), $500 \mathrm{IU} / \mathrm{ml}$ IL-4 (Schering-Plough, Kenilworth, NJ), and $10 \%$ human serum, and cultured for two days to obtain immature DCs. Mature DCs were generated by culturing immature DCs in IMDM supplemented with $100 \mathrm{ng} / \mathrm{ml}$ GM-CSF, $10 \mathrm{ng} / \mathrm{ml}$ TNFalpha (CellGenix, Freiburg, Germany), $10 \mathrm{ng} / \mathrm{ml}$ IL-1b (Bioscource Invitrogen, Camarillo, CA), 10 ng/ml IL-6 (Sandoz Novartis Pharma), $1 \mu \mathrm{g} / \mathrm{ml}$ PGE-2 (Sigma Aldrich, St. Louis, MO), $500 \mathrm{IU} / \mathrm{ml} \mathrm{INF-} \gamma$ (Boehringer Ingelheim, Ingelheim am Rhein, Germany), and 10\% human serum for an additional two days. Type I and II macrophages were in vitro differentiated from CD $14^{+}$monocytes. CD $14^{+}$monocytes were cultured for 8 days in IMDM containing $10 \%$ human serum in the presence of $50 \mathrm{ng} / \mathrm{ml} \mathrm{GM-CSF}$ or $5 \mathrm{IU} / \mathrm{ml}$ CSF-1 (R\&D Systems, Minneapolis, MN) to obtain type I or II macrophages, respectively. Activated CD19+ B-cells were generated by co-culturing $\mathrm{CD} 19^{+}$cells on CD40Ltransduced irradiated (70 Gy) mouse-fibroblasts for 7 days in IMDM supplemented with $2 \mathrm{ng} / \mathrm{ml} \mathrm{IL-4}$ and 10\% human serum. K562 cells expressing HLA-B7 (K562-B7) were previously described [31]. ALL cell lines were previously described [37]. Fibroblasts, keratinocytes and proximal tubular epithelial cells (PTECs) were cultured 
either in the absence or presence of $200 \mathrm{IU} / \mathrm{ml} \mathrm{IFN}-\gamma$ for four days before cells were used in experiments. All cells were washed twice before use in experiments.

\section{Generation of peptide-MHC complexes}

Peptide CD22 $2_{\mathrm{RPF}}$ was synthesized in-house using standard Fmoc chemisty. Recombinant HLA-B7 heavy chain and human $\beta_{2} \mathrm{~m}$ light chain were in-house produced in Escherichia coli. MHC class I refolding was performed as previously described with minor modifications [38]. MHC class I complexes were purified by gel-filtration using HPLC. pMHC-tetramers were generated by labeling biotinylated pMHC-monomers with streptavidinecoupled phycoerythrin (PE; Invitrogen, Carlsbad, CA) or allophycocyanin (APC, Invitrogen). Complexes were stored at $4^{\circ} \mathrm{C}$.

\section{Isolation of CD22-reactive T-cell clones}

T-cells binding to CD22-specific pMHC-tetramers composed of peptide CD22 $2_{\mathrm{RPF}}$ bound to HLA-B7 were isolated from PBMCs of healthy HLA-B $7^{\text {neg }}$ individuals. PBMCs were first incubated with PE-labeled pMHCtetramers for $1 \mathrm{~h}$ at $4^{\circ} \mathrm{C}$. Cells were washed twice and incubated with anti-PE-microbeads (Miltenyi Biotec) for $15 \mathrm{~min}$ at $4^{\circ} \mathrm{C}$. PE-labeled cells were isolated on an LS colomn (Miltenyi Biotec) according to manufacturer's instruction. Positively selected cells were stained with an Alexa700-labelled antibody against CD8 (Invitrogen/ Calteg, Buckingham, United Kingdom) in combination with FITC-conjugated antibodies against CD4, CD14, and CD19 (BD Pharmingen, San Jose, CA). Using a ArialII cell sorter (BD Biosciences, Franklin Lakes, NJ) and Diva Software (BD Biosciences), pMHC-tetramer ${ }^{+}$ $\mathrm{CD} 8^{+} \mathrm{T}$-cells were single-cell sorted into round-bottom 96-well plates containing $5 \times 10^{4}$ irradiated ( $35 \mathrm{~Gy}$ ) feeders in $100 \mu \mathrm{l}$ T-cell medium supplemented with $0.8 \mu \mathrm{g} / \mathrm{ml}$ PHA.

\section{TCR gene transfer}

TCRAV and TCRBV usage of T-cell clone 9D4 was determined by reverse transcriptase (RT)-PCR and sequencing using a previously established protocol [39]. V(D)J segments of the TCR alpha and TCR beta chain were codon optimized and cloned into the modified MP71TCR-flex retroviral backbone. To increase expression and preferential pairing of the introduced TCR alpha and beta chain, the MP71-TCR-flex vector contained codonoptimized and cysteine-modified murine TCR alpha and beta constant domains and a porcine teschovirus-derived P2A sequence to link TCR chains [40]. A complete construct was ordered from GenScript (Piscataway, NJ).

Purified $\mathrm{CD} 8^{+} \mathrm{T}$-cells were activated using irradiated autologous PBMCs and PHA. On day 2 following stimulation, retroviral supernatant containing either TCR-9D4 or an empty backbone (Mock) was loaded on 24-well nontissue culture-treated plates that had been coated with $30 \mathrm{mg} / \mathrm{mL}$ retronectine (Takara, Shiga, Japan) and blocked with 2\% human serum albumin (Sanquin Reagents, Amsterdam, The Netherlands). Viral supernatant was spun down at $2000 \mathrm{~g}$ for 20 minutes at $4^{\circ} \mathrm{C}$ before activated T-cells were added to retroviral supernatant and incubated at $37^{\circ} \mathrm{C}$ for 18 hours. 7 days after stimulation, high-purity TCR-transduced T-cells were obtained by MACS isolation based on the expression of the transduced TCR or marker gene nerve growth factor-receptor (NGF-R also known as CD271). Transduced T-cells were incubated with an APC-labelled antibody against the murine constant TCR domain (BD Pharmingen) or NGF-R (Sanbio, Uden, The Netherlands) for $15 \mathrm{~min}$ at $4{ }^{\circ} \mathrm{C}$ and washed twice. Following incubation with anti-APC microbeads (Miltenyi Biotec) for $15 \mathrm{~min}$ at $4^{\circ} \mathrm{C}$, TCR-transduced T-cells were isolated on a LS column following manufacturer's instructions.

\section{FACS analysis}

FACS acquisition was performed on a LSRII (BD Biosciences) or a FACS Calibur (BD Biosciences) and was analyzed using Diva Software (BD Biosciences) or FlowJo Software (TreeStar, Ashland, OR). Isolated T-cell clones were analyzed for binding to specific pMHCtetramers and CD8 expression by staining with PE-labelled pMHC-tetramers, and an Alexa700-conjugated antibody against CD8 (Invitrogen/Calteg) combined with FITClabelled antibodies against CD4, CD14, and CD19 (BD Pharmingen). 10,000 cells of a T-cell clone were first incubated with $2 \mu \mathrm{g} / \mathrm{ml} \mathrm{pMHC}$-tetramers for $15 \mathrm{~min}$ at $37^{\circ} \mathrm{C}$ before antibodies were added and incubated for an additional $15 \mathrm{~min}$ at $4^{\circ} \mathrm{C}$. Similarly, 25,000 TCR-transduced or mock-transduced T-cells were incubated with $2 \mu \mathrm{g} / \mathrm{ml}$ pMHC-tetramers for $15 \mathrm{~min}$ at $37^{\circ} \mathrm{C}$ before antibodies against CD8, CD4, NGF-R or murine TCR beta constant domain were added and incubated at $4^{\circ} \mathrm{C}$ for $15 \mathrm{~min}$. PBMCs, purified hematopoietic cell subsets or activated cells were stained with antibodies against $\mathrm{CD} 3, \mathrm{CD} 4, \mathrm{CD} 14$, CD19, CD34 (BD Pharmingen), CD22 (clone S-HCL-1, BD Pharmingen) or an isotype control for $4^{\circ} \mathrm{C}$ for $15 \mathrm{~min}$.

\section{Functional analysis}

K562 cells were peptide-pulsed at titrated peptide concentrations for $30 \mathrm{~min}$ at $37^{\circ} \mathrm{C}$. Responder T-cells and peptide-pulsed or unloaded stimulator cells were coincubated at various responder-to-stimulator ratios. After 18 hours coincubation, supernatants were harvested and IFN- $\gamma$ or GM-CSF production was measured by enzymelinked immunosorbent assay (ELISA, Sanquin Reagents or R\&D Systems, respectively). 


\section{FACS-based cytotoxicity assay}

Adapted from Jedema et al. [41], 10,000 PKH26GLlabelled (Sigma-Aldrich) target cells were co-incubated with T-cells at various effector-to-target ratios in $50 \mu \mathrm{l}$ T-cell medium for 20 hours. After coincubation, cells were stained with Sytox Blue dead cell stain (Invitrogen/Caltag) in a final concentration of $1 \mu \mathrm{M}$ for 5 min. $10 \mu \mathrm{l}$ Flowcount fluorospheres (Beckman Coulter, Brea, CA) were added and samples were analyzed using FACS. For each sample, 3,300 Flow-count fluorospheres were acquired and the percent surviving cells was calculated as follows: [(PKH26GL-labelled targets in the presence of effector cells)/(PKH26GL-labelled targets in absence of effector cells) $] \times 100 \%$.

\section{Quantitative real-time PCR of CD22}

From isolated cell subsets or cultured cells, total RNA was isolated using the RNAqueous MicroKit and Small Scale Kit (Ambion, Life Technologies) for a maximum of $0.5 \times 10^{6}$ and $10 \times 10^{6}$ cells, respectively, following manufacturer's instructions. Total RNA was converted to cDNA using M-MLV reverse transcriptase (Invitrogen). CD22 expression was measured on the Roche Lightcycler 480 (Roche) using Fast Start TaqDNA Polymerase (Roche) and EvaGreen (Biotium, Hayward, CA) with forward primer 5'-CGACGTTGGAAGAGGACACA-3' and reverse primer 5'-GGGGGCCCTTCTAACCTTTT-3'.

\section{ACKNOWLEDGMENTS}

The authors thank Guido de Roo and Sabrina A.J. Veld (Department of Hematology, Leiden University Medical Center, Leiden, The Netherlands) for providing expert technical assistance in flow cytometric cell sorting; Carsten Linnemann and Ton M. Schumacher (Division of Immunology, The Netherlands Cancer Institute, Amsterdam, The Netherlands) for providing the MP71TCR-flex retroviral backbone.

\section{CONFLICTS OF INTEREST}

The authors declare no competing interests.

\section{Authors' contributions}

L.J. designed, performed, analyzed and interpreted all experiments and wrote the manuscript. R.S.H. determined TRAV and TRBV usage and constructed retroviral expression vectors, and designed and performed qRT-PCR. D.M.v.d.S. generated pMHC-monomers, and performed and analyzed experiments P.H. designed study. M.G.D.K. identified CD22 epitope. M.P.S. and D.d.R performed experiments. P.A.v.V. designed and co-supervised study. J.H.F.F. designed and supervised study, and wrote the manuscript. M.H.M.H. analyzed and interpreted experiments, designed and supervised study, and wrote the manuscript. All authors revised and edited the manuscript.

\section{GRANT SUPPORT}

This research was supported by the financial assistance of the Dutch Cancer Society (2010-4832) and the Landsteiner Foundation for Blood Transfusion Research (LSBR0713).

\section{REFERENCES}

1. Grupp SA, Kalos M, Barrett D, Aplenc R, Porter DL, Rheingold SR, Teachey DT, Chew A, Hauck B, Wright JF, Milone $\mathrm{MC}$, Levine $\mathrm{BL}$, June $\mathrm{CH}$. Chimeric antigen receptor-modified $\mathrm{T}$ cells for acute lymphoid leukemia. N Engl J Med. 2013; 368:1509-1518.

2. Kalos M, Levine BL, Porter DL, Katz S, Grupp SA, Bagg A, June CH. T cells with chimeric antigen receptors have potent antitumor effects and can establish memory in patients with advanced leukemia. Sci Transl Med. 2011; 3:95ra73.

3. Porter DL, Levine BL, Kalos M, Bagg A, June CH. Chimeric antigen receptor-modified $\mathrm{T}$ cells in chronic lymphoid leukemia. N Engl J Med. 2011; 365:725-733.

4. Kochenderfer JN, Wilson WH, Janik JE, Dudley ME, StetlerStevenson M, Feldman SA, Maric I, Raffeld M, Nathan DA, Lanier BJ, Morgan RA, Rosenberg SA. Eradication of B-lineage cells and regression of lymphoma in a patient treated with autologous $\mathrm{T}$ cells genetically engineered to recognize CD19. Blood. 2010; 116:4099-4102.

5. Coiffier B, Lepage E, Briere J, Herbrecht R, Tilly H, Bouabdallah R, Morel P, Van Den Neste E, Salles G, Gaulard P, Reyes F, Lederlin P, Gisselbrecht C. CHOP chemotherapy plus rituximab compared with CHOP alone in elderly patients with diffuse large-B-cell lymphoma. N Engl J Med. 2002; 346:235-242.

6. McLaughlin P, Grillo-Lopez AJ, Link BK, Levy R, Czuczman MS, Williams ME, Heyman MR, BenceBruckler I, White CA, Cabanillas F, Jain V, Ho AD, Lister J, et al. Rituximab chimeric anti-CD20 monoclonal antibody therapy for relapsed indolent lymphoma: half of patients respond to a four-dose treatment program. J Clin Oncol. $1998 ; 16: 2825-2833$.

7. Witzig TE, Vukov AM, Habermann TM, Geyer S, Kurtin PJ, Friedenberg WR, White WL, Chalchal HI, Flynn PJ, Fitch TR, Welker DA. Rituximab therapy for patients with newly diagnosed, advanced-stage, follicular grade I non-Hodgkin's lymphoma: a phase II trial in the North Central Cancer Treatment Group. J Clin Oncol. 2005; 23:1103-1108.

8. Vose JM, Link BK, Grossbard ML, Czuczman M, GrilloLopez A, Gilman P, Lowe A, Kunkel LA, Fisher RI. Phase II 
study of rituximab in combination with chop chemotherapy in patients with previously untreated, aggressive nonHodgkin's lymphoma. J Clin Oncol. 2001; 19:389-397.

9. Kochenderfer JN, Dudley ME, Feldman SA, Wilson WH, Spaner DE, Maric I, Stetler-Stevenson M, Phan GQ, Hughes MS, Sherry RM, Yang JC, Kammula US, Devillier L, et al. B-cell depletion and remissions of malignancy along with cytokine-associated toxicity in a clinical trial of anti-CD19 chimeric-antigen-receptortransduced T cells. Blood. 2012; 119:2709-2720.

10. Shortt J, Spencer A. Adjuvant rituximab causes prolonged hypogammaglobulinaemia following autologous stem cell transplant for non-Hodgkin's lymphoma. Bone Marrow Transplant. 2006; 38:433-436.

11. Wolverton W, McClenathan B. Prolonged hypogammaglobulinemia after adjuvant rituximab for Hodgkin's lymphoma presenting with refractory urticaria. Ann Allergy Asthma Immunol. 2012; 109:473-474.

12. Grupp SA, Maude SL, Shaw PA, Aplenc R, Barrett DM, Callahan C, Lacey SF, Levine BL, Melenhorst JJ, Motley L, Rheingold SR, Teachey DT, Wood PA, et al. Durable Remissions in Children with Relapsed/Refractory ALL Treated with T Cells Engineered with a CD19-Targeted Chimeric Antigen Receptor (CTL019). Blood. 2015; 126:681-681.

13. Martin A, Conde E, Arnan M, Canales MA, Deben G, Sancho JM, Andreu R, Salar A, Garcia-Sanchez P, Vazquez L, Nistal S, Requena MJ, Donato EM, et al. R-ESHAP as salvage therapy for patients with relapsed or refractory diffuse large B-cell lymphoma: the influence of prior exposure to rituximab on outcome. A GEL/TAMO study. Haematologica. 2008; 93:1829-1836.

14. Sgroi D, Varki A, Braesch-Andersen S, Stamenkovic I. CD22, a B cell-specific immunoglobulin superfamily member, is a sialic acid-binding lectin. J Biol Chem. 1993; 268:7011-7018.

15. Otipoby KL, Draves KE, Clark EA. CD22 regulates B cell receptor-mediated signals via two domains that independently recruit Grb2 and SHP-1. J Biol Chem. 2001; 276:44315-44322.

16. Haso W, Lee DW, Shah NN, Stetler-Stevenson M, Yuan CM, Pastan IH, Dimitrov DS, Morgan RA, FitzGerald DJ, Barrett DM, Wayne AS, Mackall CL, Orentas RJ. Anti-CD22-chimeric antigen receptors targeting B-cell precursor acute lymphoblastic leukemia. Blood. 2013; 121:1165-1174.

17. Raetz EA, Cairo MS, Borowitz MJ, Blaney SM, Krailo MD, Leil TA, Reid JM, Goldenberg DM, Wegener WA, Carroll WL, Adamson PC and Children's Oncology Group Pilot S. Chemoimmunotherapy reinduction with epratuzumab in children with acute lymphoblastic leukemia in marrow relapse: a Children's Oncology Group Pilot Study. J Clin Oncol. 2008; 26:3756-3762.

18. Advani A, Coiffier B, Czuczman MS, Dreyling M, Foran J, Gine E, Gisselbrecht C, Ketterer N, Nasta S, Rohatiner A,
Schmidt-Wolf IG, Schuler M, Sierra J, et al. Safety, pharmacokinetics, and preliminary clinical activity of inotuzumab ozogamicin, a novel immunoconjugate for the treatment of B-cell non-Hodgkin's lymphoma: results of a phase I study. J Clin Oncol. 2010; 28:2085-2093.

19. Kantarjian H, Thomas D, Jorgensen J, Jabbour E, Kebriaei P, Rytting M, York S, Ravandi F, Kwari M, Faderl S, Rios MB, Cortes J, Fayad L, et al. Inotuzumab ozogamicin, an anti-CD22-calecheamicin conjugate, for refractory and relapsed acute lymphocytic leukaemia: a phase 2 study. Lancet Oncol. 2012; 13:403-411.

20. Morgan RA, Dudley ME, Wunderlich JR, Hughes MS, Yang JC, Sherry RM, Royal RE, Topalian SL, Kammula US, Restifo NP, Zheng Z, Nahvi A, de Vries CR, et al. Cancer regression in patients after transfer of genetically engineered lymphocytes. Science. 2006; 314:126-129.

21. Robbins PF, Morgan RA, Feldman SA, Yang JC, Sherry RM, Dudley ME, Wunderlich JR, Nahvi AV, Helman LJ, Mackall CL, Kammula US, Hughes MS, Restifo NP, et al. Tumor regression in patients with metastatic synovial cell sarcoma and melanoma using genetically engineered lymphocytes reactive with NYESO-1. J Clin Oncol. 2011; 29:917-924.

22. Hassan C, Kester MG, Ru AH, Hombrink P, Drijfhout JW, Nijveen H, Leunissen JA, Heemskerk MH, Falkenburg JH, Veelen PA. The human leukocyte antigen-presented ligandome of B lymphocytes. Mol Cell Proteomics. 2013.

23. Nielsen M, Lundegaard C, Worning P, Lauemoller SL, Lamberth K, Buus S, Brunak S, Lund O. Reliable prediction of T-cell epitopes using neural networks with novel sequence representations. Protein Sci. 2003; 12:1007-1017.

24. Lundegaard C, Lamberth K, Harndahl M, Buus S, Lund O, Nielsen M. NetMHC-3.0: accurate web accessible predictions of human, mouse and monkey MHC class I affinities for peptides of length 8-11. Nucleic Acids Res. 2008; 36:W509-W512.

25. van Loenen MM, de Boer R, Amir AL, Hagedoorn RS, Volbeda GL, Willemze R, van Rood JJ, Falkenburg JH, Heemskerk MH. Mixed T cell receptor dimers harbor potentially harmful neoreactivity. Proc Natl Acad Sci USA. 2010; 107:10972-10977.

26. Amir AL, van der Steen DM, Hagedoorn RS, Kester MG, van Bergen CA, Drijfhout JW, de Ru AH, Falkenburg JH, van Veelen PA, Heemskerk MH. Allo-HLA-reactive $\mathrm{T}$ cells inducing graft-versus-host disease are single peptide specific. Blood. 2011; 118:6733-6742.

27. Amir AL, van der Steen DM, van Loenen MM, Hagedoorn RS, de Boer R, Kester MD, de Ru AH, Lugthart GJ, van Kooten C, Hiemstra PS, Jedema I, Griffioen M, van Veelen PA, et al. PRAME-specific AlloHLA-restricted $\mathrm{T}$ cells with potent antitumor reactivity useful for therapeutic T-cell receptor gene transfer. Clin Cancer Res. 2011; 17:5615-5625.

28. Savage P, Gao L, Vento K, Cowburn P, Man S, Steven N, Ogg G, McMichael A, Epenetos A, Goulmy E, Stauss HJ. 
Use of B cell-bound HLA-A2 class I monomers to generate high-avidity, allo-restricted CTLs against the leukemiaassociated protein Wilms tumor antigen. Blood. 2004; 103:4613-4615.

29. Abrahamsen IW, Stronen E, Walchli S, Johansen JN, Kjellevoll S, Kumari S, Komada M, Gaudernack G, Tjonnfjord $G$, Toebes $M$, Schumacher TN, LundJohansen F, Olweus J. Targeting B cell leukemia with highly specific allogeneic $\mathrm{T}$ cells with a public recognition motif. Leukemia. 2010; 24:1901-1909.

30. Spranger S, Jeremias I, Wilde S, Leisegang M, Starck L, Mosetter B, Uckert W, Heemskerk MH, Schendel DJ, Frankenberger B. TCR-transgenic lymphocytes specific for HMMR/Rhamm limit tumor outgrowth in vivo. Blood. 2012; 119:3440-3449.

31. Jahn L, Hombrink P, Hassan C, Kester MG, van der Steen DM, Hagedoorn RS, Falkenburg JH, van Veelen PA, Heemskerk MH. Therapeutic targeting of the BCRassociated protein CD79b in a TCR-based approach is hampered by aberrant expression of CD79b. Blood. 2015; 125:949-958.

32. Straathof KC, Pule MA, Yotnda P, Dotti G, Vanin EF, Brenner MK, Heslop HE, Spencer DM, Rooney CM. An inducible caspase 9 safety switch for T-cell therapy. Blood. 2005; 105:4247-4254.

33. Ciceri F, Bonini C, Stanghellini MT, Bondanza A, Traversari C, Salomoni M, Turchetto L, Colombi S, Bernardi M, Peccatori J, Pescarollo A, Servida P, Magnani Z, et al. Infusion of suicide-gene-engineered donor lymphocytes after family haploidentical haemopoietic stemcell transplantation for leukaemia (the TK007 trial): a nonrandomised phase I-II study. Lancet Oncol. 2009; 10:489-500.

34. Di Stasi A, Tey SK, Dotti G, Fujita Y, Kennedy-Nasser A, Martinez C, Straathof K, Liu E, Durett AG, Grilley B, Liu H, Cruz CR, Savoldo B, et al. Inducible apoptosis as a safety switch for adoptive cell therapy. N Engl J Med. 2011; 365:1673-1683.

35. Reineks EZ, Osei ES, Rosenberg A, Auletta J, Meyerson HJ. CD22 expression on blastic plasmacytoid dendritic cell neoplasms and reactivity of anti-CD22 antibodies to peripheral blood dendritic cells. Cytometry B Clin Cytom. 2009; 76:237-248.

36. Stone JD, Aggen DH, Schietinger A, Schreiber H, Kranz DM. A sensitivity scale for targeting $\mathrm{T}$ cells with chimeric antigen receptors (CARs) and bispecific T-cell Engagers (BiTEs). Oncoimmunology. 2012; 1:863-873.

37. Nijmeijer BA, Szuhai K, Goselink HM, van Schie ML, van der Burg M, de JD, Marijt EW, Ottmann OG, Willemze R, Falkenburg JH. Long-term culture of primary human lymphoblastic leukemia cells in the absence of serum or hematopoietic growth factors. Exp Hematol. 2009; 37:376-385.

38. Garboczi DN, Hung DT, Wiley DC. HLA-A2-peptide complexes: refolding and crystallization of molecules expressed in Escherichia coli and complexed with single antigenic peptides. Proc Natl Acad Sci USA. 1992; 89:3429-3433.

39. Heemskerk MH, de Paus RA, Lurvink EG, Koning F, Mulder A, Willemze R, van Rood JJ, Falkenburg JH. Dual HLA class I and class II restricted recognition of alloreactive $\mathrm{T}$ lymphocytes mediated by a single $\mathrm{T}$ cell receptor complex. Proc Natl Acad Sci USA. 2001; 98:6806-6811.

40. Linnemann C, Heemskerk B, Kvistborg P, Kluin RJ, Bolotin DA, Chen X, Bresser K, Nieuwland M, Schotte R, Michels S, Gomez-Eerland R, Jahn L, Hombrink P, et al. High-throughput identification of antigen-specific TCRs by TCR gene capture. Nat Med. 2013; 19:1534-1541.

41. Jedema I, van der Werff NM, Barge RM, Willemze R, Falkenburg JH. New CFSE-based assay to determine susceptibility to lysis by cytotoxic $\mathrm{T}$ cells of leukemic precursor cells within a heterogeneous target cell population. Blood. 2004; 103:2677-2682. 